\title{
Impact of Anomalous Ocean Heat Transport on the North Atlantic Oscillation
}

\author{
Fabio D'Andrea, Arnaud Czaja, and John Marshall \\ Department of Earth, Atmospheric, and Planetary Sciences, Massachusetts Institute of Technology, Cambridge, Massachusetts
}

(Manuscript received 4 January 2005, in final form 10 May 2005)

\begin{abstract}
Coupled atmosphere-ocean dynamics in the North Atlantic is studied by means of a simple model, featuring a baroclinic three-dimensional atmosphere coupled to a slab ocean. Anomalous oceanic heat transport due to wind-driven circulation is parameterized in terms of a delayed response to the change in wind stress curl due to the North Atlantic Oscillation (NAO). Climate variability for different strengths of ocean heat transport efficiency is analyzed. Two types of behavior are found depending on time scale. At interdecadal and longer time scales, a negative feedback is found that leads to a reduction in the spectral power of the NAO. By greatly increasing the efficiency of ocean heat transport, the NAO in the model can be made to completely vanish from the principal modes of variability at low frequency. This suggests that the observed NAO variability at these time scales must be due to mechanisms other than the interaction with wind-driven circulation. At decadal time scales, a coupled oscillation is found in which SST and geopotential height fields covary.
\end{abstract}

\section{Introduction}

The spatial and temporal structure of the North Atlantic Oscillation (NAO) can be described by internal atmospheric dynamics (e.g., Feldstein 2000; Thompson et al. 2003) especially on intraseasonal time scales. Nevertheless, on longer time scales, there are a growing number of indications that the slight redness of the NAO spectrum is likely to be due to external forcing arising from the interaction of North Atlantic atmospheric variability with other components of the climate system (Czaja et al. 2003; Stephenson et al. 2000). On decadal and interdecadal time scales, one likely source of this external forcing is variability in air-sea fluxes associated with changes in the North Atlantic Ocean circulation.

The NAO drives variability in the North Atlantic Ocean, affecting the mixed layer (Frankignoul and Hasselmann 1977; Battisti et al. 1995), the wind-driven circulation (Frankignoul et al. 1997), and thermohaline circulation (Delworth and Greatbatch 2000). Moreover, evidence of the response of the NAO to North Atlantic sea surface temperature anomalies has been

Corresponding author address: Fabio D'Andrea, Laboratoire de Météorologie Dynamique, Ecole Normale Supérieure, 24, Rue Lhomond, 75005 Paris, France.

E-mail: dandrea@lmd.ens.fr found both in observations (Czaja and Frankignoul 2002; Rodwell and Folland, 2002) and in general circulation model (GCM) studies (Rodwell et al. 1999; Sutton and Hodson 2003).

To what extent there is a two-way coupled interaction between the atmosphere and ocean over the Atlantic in middle to high latitudes is not yet clear-see the discussion in Marshall et al. (2001a). The problem is made difficult by the long time scales of variation of ocean dynamics, for which few data are available, and the competing effects of many processes that make interpretation of coupled GCM integrations very difficult. For this reason much use has been made of idealized models in which processes can be studied in isolation of others. Barsugli and Battisti (1998) used a 1D model of the atmosphere-ocean mixed-layer system. They showed how temperature equilibration between the ocean and atmosphere would lead to reduced heat flux on long time scales and hence reduced damping of anomalies. This would foster SST and atmospheric variability at low frequencies, with the effect of "reddening" the NAO spectrum. Marshall et al. (2001b) and Czaja and Marshall (2001), however, added a representation of air-sea flux variability induced by interactive ocean dynamics and found a reduction of variability at low frequency and hence a "blueing" of the NAO spectrum. This phenomenon would take place, they argued, at time scales longer than a delay time $t_{d}$ dependent on 
the response time of the ocean to changes in the forcing, perhaps $10 \mathrm{yr}$.

In this paper, we revisit these idealized results with a simple, yet more realistic model. The model comprises a quasigeostrophic three-dimensional atmosphere coupled to a slab ocean model. A parameterization of anomalous heat transport-a "Q flux"- due to variability in ocean circulation is included by slaving it to atmospheric circulation as a delayed response to changes in the modeled NAO.

In section 2 the model equations are briefly described. We study the modes of variability of the coupled model and the passive response of the atmospheric component to prescribed SST anomalies. The parameterization of the $Q$ flux is also described and discussed. In sections 3 and 4 we analyze the coupled response to the $Q$ flux parameterization. Section 3 concentrates on interdecadal time scales, and section 4 concentrates on decadal time scales. We summarize, discuss, and conclude in section 5 .

\section{Model and methodology}

\section{a. Model formulation}

The model is of intermediate complexity. The atmospheric component, taken from Marshall and Molteni (1993, hereafter MM93), is based on the quasigeostrophic (QG) potential vorticity (PV) equation on the sphere, discretized on three vertical levels $(200,500$, and $800 \mathrm{hPa}$ ), at a spectral horizontal resolution of T21. The ocean comprises a slab SST mixed layer forced by air-sea heat fluxes, Ekman advection, and a parameterization of anomalous heat transport by ocean circulation. Atmosphere and ocean are coupled via a surface flux of sensible and latent heat, computed using bulk aerodynamic formulas, that forces the mixed layer on the ocean side and induces a potential vorticity forcing in the atmospheric model on the other.

The MM93 model has been used in a number of studies of atmospheric dynamics, data assimilation, and atmospheric predictability. Despite its simplicity, the model has a remarkably good climatology and variability with a plausible stationary wave pattern, Pacific and Atlantic storm tracks, and maxima in low-frequency activity at the end of the storm tracks. D'Andrea and Vautard (2000) show comparisons of the model climatology with observations. A coupled version similar to that described here was used by Ferreira and Frankignoul (2005) to study the transient response of the atmosphere to SST anomalies.

The equation for the atmosphere is

$$
\frac{D q}{D t}=S+S^{\prime}\left(Q_{s}\right)-D,
$$

where $D / D t$ represents the total derivative and $q$ is the quasigeostrophic potential vorticity on the sphere discretized on three levels. Dissipation is represented by $D$, and $S$ and $S^{\prime}$ are source terms. The full vertically discretized expression of the atmospheric equations of the model is given in appendix A.

Here, $S$ is a spatially varying time-independent forcing designed to represent sources of potential vorticity that result from processes not explicitly included in the model. It is constructed empirically as in MM93 (see appendix B) to keep the model's mean state close to that of an observed wintertime climatology.

The additional source term $S^{\prime}\left(Q_{s}\right)$ represents the PV forcing induced by the air-sea surface heat flux $Q_{s}$. As described in detail in appendix $\mathrm{A}$, the heat flux has the effect of changing the thickness of the atmospheric quasigeostrophic layers; a flux out of the ocean ${ }^{1}$ induces an increase in thickness, that is, a negative streamfunction anomaly at $800 \mathrm{mb}$, and a positive streamfunction anomaly at $500 \mathrm{mb}$. Note that the net PV forcing by anomalous air-sea heat flux is zero: when integrated over all levels of the atmospheric model, the vertical integral is exactly zero.

The turbulent air-sea heat flux $Q_{s}$ is given by the bulk formula

$$
Q_{s}=\rho_{a} c_{p a}\left(1+\frac{1}{B}\right)\left|u_{s}\right| C_{D}\left(T_{a}-\mathrm{SST}\right),
$$

where $\left|u_{s}\right|$ is the surface wind speed, which is taken equal to the wind at the lowest level $(800 \mathrm{mb})$, and $T_{a}$ is the surface air temperature. Here, $T_{a}$ is computed by $T_{a}=k T_{2}$, where $T_{2}$ is the temperature in the 500-800mb layer and $k$ is a constant coefficient that is tuned; $B$ is the Bowen ratio, parameterizing the effect of latent heat flux, that is taken equal to 0.5 .

In this study coupling between the mixed layer and the atmosphere is implemented only over the North Atlantic basin, thus precluding study of Pacific coupled air-sea interaction or variability in the Pacific driven by the Atlantic. The SST equation is given by

$$
\frac{\partial}{\partial t} \mathrm{SST}=\frac{1}{\rho_{o} c_{p o} h_{m}}\left(Q_{s}+Q_{\mathrm{ek}}+Q_{g}^{\prime}+S_{c}\right)
$$

where $Q_{\mathrm{ek}}$ is the advection of the mean observed sea surface temperature gradient $\widehat{\text { SST }}$ (where the hat indicates "observed") by Ekman currents:

$$
Q_{\mathrm{ek}}=\rho_{o} c_{p o} h_{m} \mathbf{V}_{\mathrm{ek}} \cdot \nabla \overline{\overline{\mathrm{SST}}},
$$

\footnotetext{
${ }^{1}$ We adopt the following convention: $Q_{s}$ is positive if directed into the ocean, thus warming the ocean and cooling the atmosphere.
} 
and $\mathbf{V}_{\mathrm{ek}}$ is given by

$$
\mathbf{V}_{\mathrm{ek}}=\frac{1}{\rho_{o} f_{0} h_{m}}\left(-\tau_{y}, \tau_{x}\right) \text { and } \boldsymbol{\tau}=\rho_{\mathrm{o}} C_{D}\left|u_{s}\right| \mathbf{u}_{s},
$$

where $\mathbf{u}_{s}$ is taken, as above, from the model's wind at $800 \mathrm{hPa}$.

In the SST equation, $S_{c}$ is a flux correction term defined in a similar way to the term $S$ of the PV equation, as described in appendix B. Geostrophic advection of heat by the ocean is represented by $Q_{g}^{\prime}$ and is parameterized as described in section $2 b$.

A list of symbols and values of model parameters (for both the atmosphere and ocean) is given in Table 1; they are in general taken from the wintertime standard U.S. atmosphere.

\section{DOMINANT PATTERNS OF OCEAN-ATMOSPHERE INTERACTION}

As a preliminary illustration of the dynamics of the coupled model, the first empirical orthogonal function (EOF) of the monthly mean SST, and 500-hPa streamfunction anomaly over the Euro-Atlantic region are shown in Fig. 1. To produce this figure, an extended integration of the model was performed setting $Q_{g}^{\prime}=0$ in Eq. (3). The streamfunction EOF has a dipolar structure reminiscent of the NAO. This map is in fact the Atlantic portion of a rather zonally symmetric annular mode that results from hemispheric EOF analysis (not shown). The pattern of the first SST EOF also shows a dipolar structure with zero line around $50^{\circ} \mathrm{N}$ explaining around $37 \%$ of variance. The main difference between

TABLE 1 . Key model parameters and their values.

\begin{tabular}{|c|c|c|}
\hline Symbol & Meaning & Value \\
\hline$h_{a}$ & $\begin{array}{l}\text { Thickness of the } 500-800-\mathrm{mb} \\
\text { layer }\end{array}$ & $3500 \mathrm{~m}$ \\
\hline$\sigma_{1}$ & $\begin{array}{l}\text { Vertical stability parameters in } \\
\text { the } 1-2 \text { layer }\end{array}$ & $5.78 \times 10^{-6} \mathrm{~s}^{2} \mathrm{~kg}^{-2}$ \\
\hline$\sigma_{2}$ & $\begin{array}{l}\text { Vertical stability parameters in } \\
\text { the } 2-3 \text { layer }\end{array}$ & $2.25 \times 10^{-6} \mathrm{~s}^{2} \mathrm{~kg}^{-2}$ \\
\hline$\Delta p$ & $\begin{array}{l}\text { Interval of pressure between } \\
\text { levels }\end{array}$ & $300 \mathrm{mb}$ \\
\hline$\rho_{o}$ & Ocean water density & $1030 \mathrm{~kg} \mathrm{~m}^{-3}$ \\
\hline$c_{\text {po }}$ & Ocean water specific heat & $4000 \mathrm{~J} \mathrm{~kg}^{-1} \mathrm{~K}^{-1}$ \\
\hline$h_{m}^{\text {po }}$ & $\begin{array}{l}\text { Depth of the oceanic mixed } \\
\text { layer }\end{array}$ & $100 \mathrm{~m}$ \\
\hline$\rho_{a}$ & Air density at sea level & $1.2254 \mathrm{Kg} \mathrm{m}^{-3}$ \\
\hline$c_{\mathrm{pa}}$ & Air specific heat & $1000 \mathrm{~J} \mathrm{~kg}^{-1} \mathrm{~K}^{-1}$ \\
\hline$C_{D}$ & $\begin{array}{l}\text { Bulk aerodynamic drag } \\
\text { coefficient }\end{array}$ & 0.0013 \\
\hline$R$ & Ideal gas constant & $287 \mathrm{~J} \mathrm{~kg} \mathrm{~K}^{-1}$ \\
\hline$f_{0}$ & Coriolis parameter at $45^{\circ} \mathrm{N}$ & $10^{-4} \mathrm{~s}^{-1}$ \\
\hline$B$ & Bowen ratio & 0.5 \\
\hline$k$ & Ratio of $T_{a}$ and $T_{2}$ & 1.09 \\
\hline
\end{tabular}

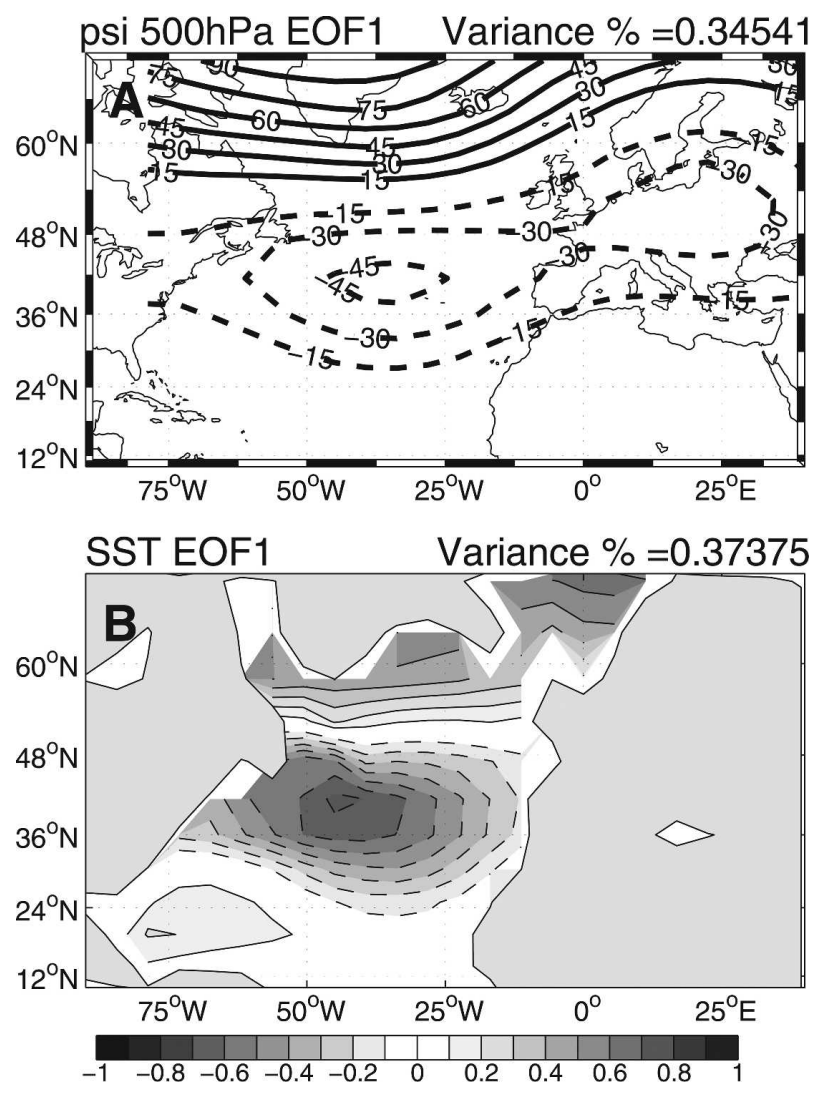

FIG. 1. First EOFs of (top) $500-\mathrm{hPa}$ streamfunction (transformed into geopotential height, contours every $15 \mathrm{~m}$, and negative contours dashed) and (bottom) SST anomaly (contours every $0.1 \mathrm{~K}$; negative contours dashed) in the control model. The fraction of variance explained is reported above each panel. The EOFs are scaled so that they display the typical amplitude of SST and 500-hPa monthly anomaly for one $\sigma$ of their respective time series.

the modeled and observed SST EOF is found in the tropical Atlantic Ocean, where observations indicate another center of variability, anticorrelated with the center of the basin, giving the classic "tripole" structure (see, e.g., Cayan 1992). The poor representation of tropical dynamics in the QG atmosphere is probably responsible for this error.

The equilibrium response to a prescribed constant SST anomaly having the same pattern and sign of SST EOF1 is shown in Fig. 2, where, for clarity, the streamfunction response of the model is transformed to geopotential height $(\mathrm{GPH})$. An SST EOF1 pattern having a maximum amplitude of two standard deviations of PC1, equivalent to a maximum value of $1.5 \mathrm{~K}$ in the southern lobe of the dipole, was prescribed, and a $2 \times$ $10^{6}$ days integration was carried out. The response is equivalent barotropic and has the form of a negative phase of the model's NAO, with a high over warm SST 

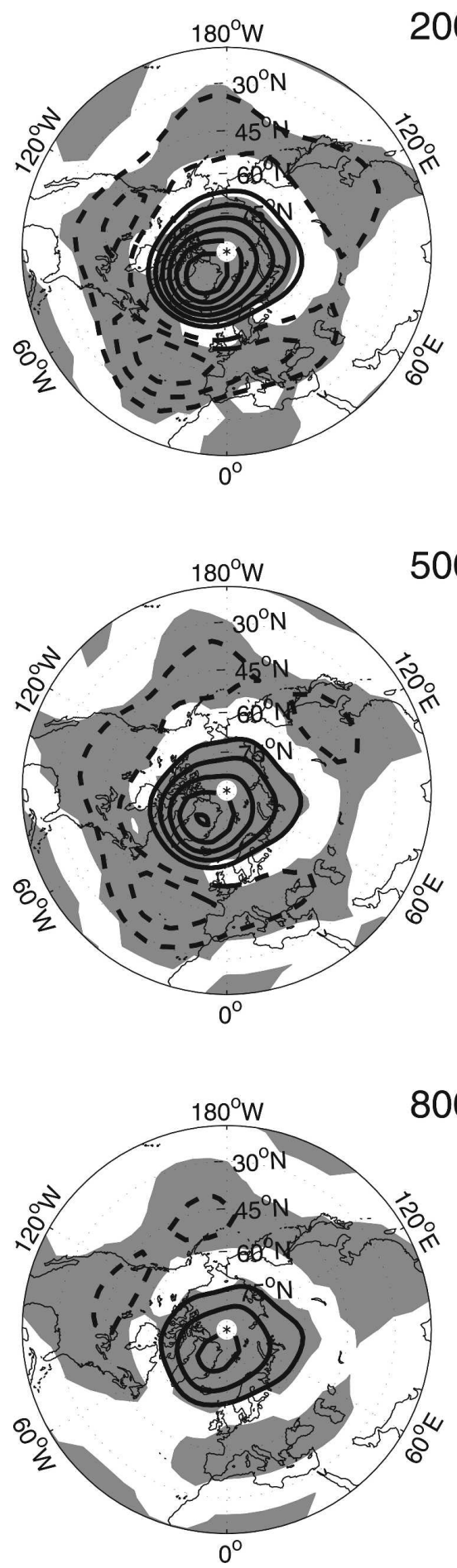

FIG. 2. Atmospheric response to a prescribed SST anomaly having the pattern of the first EOF of SST and an amplitude of $2 \sigma$. Geopotential height at three vertical levels. Contours every $5 \mathrm{~m}$, zero line omitted, and negative contours dashed. Gray shading refers to $99 \%$ confidence in a Student's $t$ test. to the north and a low over cold SST to the south. The equivalent barotropic response is due to transient eddy flux of positive (negative) vorticity over cold (warm) water. This mechanism was shown to be at work in virtually the same model as that used here by Ferreira and Frankignoul (2005). In their paper, a warm (cold) SST anomaly results in an anomalous diabatic heating (cooling) of the lower layers of the atmosphere, which creates a baroclinic response as predicted by linear theory. This initial response modifies the transient eddy activity and thus the convergence of eddy momentum and heat fluxes. The latter transforms the initial baroclinic response into an equivalent barotropic one. The full evolution from a linear baroclinic response to an equilibrium barotropic one takes place in 3 to 4 months.

Other studies of model response to SST anomalies still show a certain degree of disagreement and depend on season, geographical location, and on the model used. Nevertheless, a broad consensus seems to be emerging (see Kushnir et al. 2002 and references therein), postulating a barotropic response of 15 to 20 geopotential height meters at $500 \mathrm{hPa} \mathrm{K}^{-1}$ of SST anomaly, set by transient eddy flux. This is broadly in agreement with the behavior of our model.

\section{b. Parameterization of ocean heat transport}

To focus on the impact of geostrophic current anomalies $\mathbf{V}_{g}^{\prime}$ on the SST, we choose to define $Q_{g}^{\prime}$ in Eq. (3) as a time-dependent but spatially fixed heating/ cooling anomaly as follows:

$$
Q_{g}^{\prime}(x, y, t)=-\rho_{o} C_{p o} h_{m} \mathbf{V}_{g}^{\prime} \cdot \nabla \overline{\mathrm{SST}}=\mathbf{Q}(x, y) q(t) .
$$

In Eq. (6), $h_{m} \mathbf{V}_{g}^{\prime}$ represents the geostrophic current anomalies integrated over the depth of the mixed layer, $\boldsymbol{\nabla S S T}$ represents the mean SST gradient, $\mathbf{Q}$ is the nondimensional spatial pattern of the $Q$ flux, and $q$ is its time series, in watts per squared meters. Note that Eq. (6) does not represent the effects of mean advection by geostrophic currents and hence does not include the "spatial resonance" mechanism proposed by Saravanan and Mc Williams (1998).

The choice of the $Q$ flux pattern is meant to represent the impact of the NAO on the wind-driven circulation. As discussed in Marshall et al. (2001b; see also the recent reviews by Marshall et al. 2001a and Visbeck et al. 2003), the NAO drives an anomalous horizontal gyre straddling the mean separation of the subpolar and subtropical gyres, the so-called "intergyre" gyre. When the latter circulates anticyclonically it transports heat northward, warming the subpolar gyre and cooling the subtropical gyre. Consistent with the role of ocean currents, which can only redistribute heat and do not cre- 

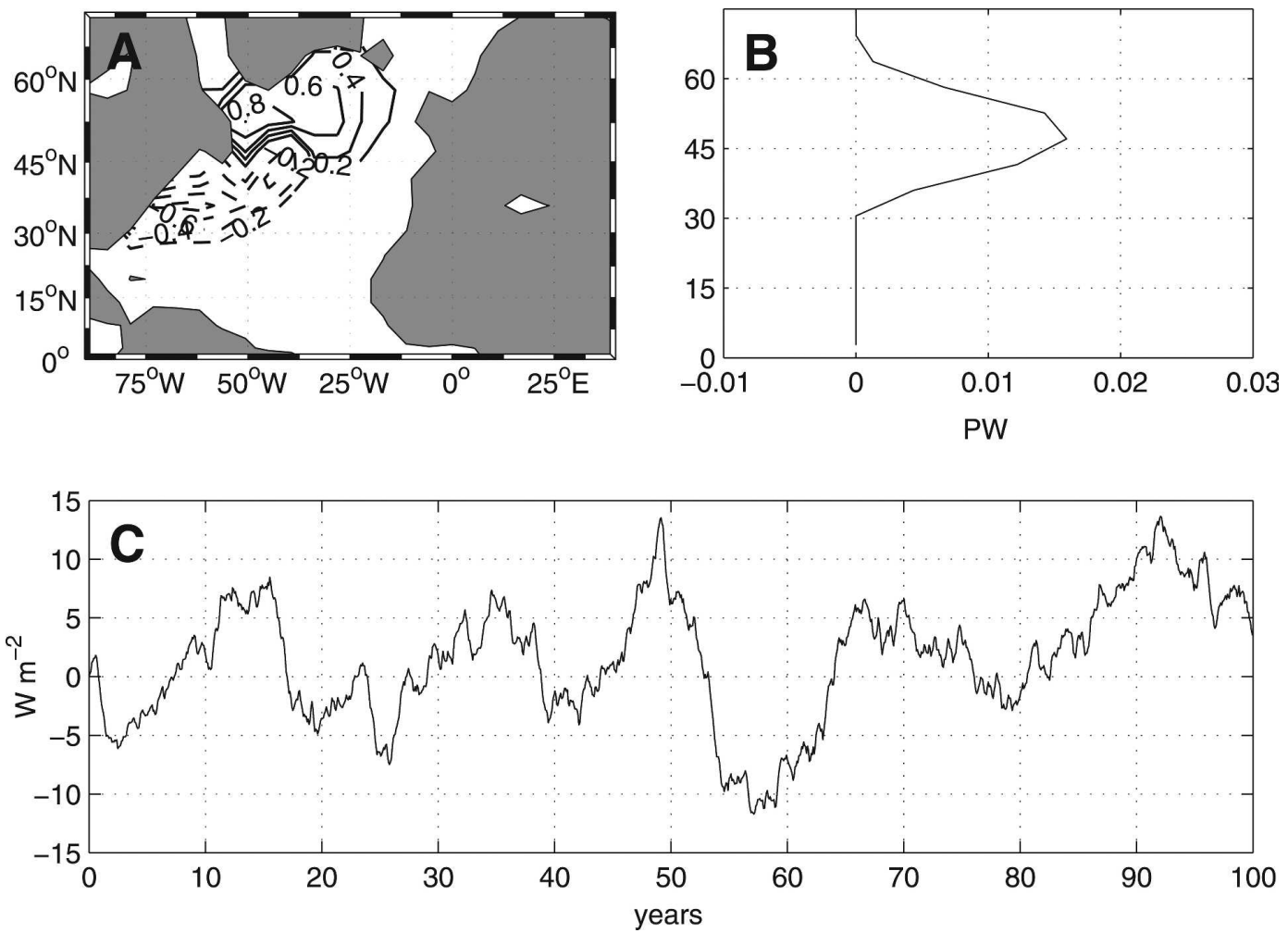

FIG. 3. (a) Prescribed anomalous heat flux dipole $\mathbf{Q}(x, y)$ normalized by dividing by its maximum value. Negative contours are dashed. (b) Latitude-longitude integral of the pattern in (a), multiplied by the standard deviation of the $Q_{g}$ time series of the weak ocean integration. (c) A section of the modulation time series $q(t)$ for the weak ocean integration.

ate net (domain averaged) heating or cooling, the spatial integral of the $Q$ flux at all times is zero.

Figure 3a displays the spatial pattern chosen for $\mathbf{Q}$. It consists of a westward intensified dipole across $45^{\circ} \mathrm{N}$ (Fig. 3a), leading, when $q(t)>0$, to a warming of the mixed layer in the subpolar gyre and a cooling in the western subtropical gyre. This configuration is associated with a net zonally averaged northward heat transport whose latitudinal distribution (imposing zero heat transport at the northern domain boundary) is shown in Fig. 3b. In this panel, the labeling of the $x$ axis in PW corresponds to a standard deviation of ocean heat transport for the "weak ocean" integration, as discussed below.

Although the $Q$ flux parameterization could be closed by using the model SST gradient and surface wind stress curl, together with a simple dynamical balance to relate the latter to changes in the strength of the intergyre gyre, we simply choose to relate $q(t)$ to a model NAO index $I_{\text {NAO }}$ through

$$
q(t)=g \int_{t-t_{d}}^{t} I_{\mathrm{NAO}}\left(t^{\prime}\right) \frac{d t^{\prime}}{t_{d}} .
$$

In Eq. (7), we have introduced a parameter $g$ measuring the efficiency with which the intergyre gyre carries heat across the subpolar and subtropical gyres, and a time scale $t_{d}=10 \mathrm{yr}$; our choice of $g$ is discussed in the next section. Equation (7) simply states that if on average the NAO is positive over the previous $t_{d}$ years (enhanced westerlies), the intergyre circulates anticyclonically and warms (cools) the subpolar (subtropical) gyre. Such a form can be justified from linear Sverdrup dynamics (see Marshall et al. 2001b) and the delay identified with the spinup time of the intergyre gyre, or equivalently, the time it takes for long baroclinic Rossby waves to cross the North Atlantic basin from east to west in midlatitudes (about $10 \mathrm{yr}$ ). As emphasized in Frankignoul et al. (1997), the model (7) leads to a red oceanic spectrum as a response to (an essentially) white atmospheric forcing.

In Eq. (7), $I_{\mathrm{NAO}}$ is defined as the projection of the model's monthly mean streamfunction on the first EOF of the control integration in Fig. 1, normalized by its 10 -yr-mean standard deviation. Since $\mathbf{Q}$ reaches a maximum of +1 , if the NAO has an amplitude of one standard deviation lasting over a time interval of $t_{d}$, the $Q$ 
TABLE 2. Names of the coupled model experiments and meridional heat transport standard deviation diagnosed at $47^{\circ} \mathrm{N}$.

\begin{tabular}{lcccc}
\hline & & $\begin{array}{c}\text { A } \\
\text { priori } \\
\text { heat } \\
\text { Name }\end{array}$ & $\begin{array}{c}\text { A } \\
\text { posteriori } \\
\text { heat } \\
\text { transport } \\
\text { std dev } \\
\text { transport } \\
\text { Weak ocean }\end{array}$ & $\begin{array}{c}\text { A } \\
\text { std dev } \\
\text { posteriori } \\
\text { value of } \\
\text { dipole } \\
\text { max }\end{array}$ \\
Strong ocean & 7 & 0.019 & 0.015 & $\begin{array}{c}\text { m } \\
\left(\mathrm{W} \mathrm{m}^{-2}\right)\end{array}$ \\
Very strong ocean & 48 & 0.063 & 0.043 & 16 \\
\hline
\end{tabular}

flux in Eq. (6) would be a dipole with a maximum value of $g$ (in $\mathrm{W} \mathrm{m}^{-2}$ ).

The parameter $g$ is the fundamental control parameter of our study. The larger its value, the greater the impact of ocean dynamics on SST for a given amplitude of NAO. For very large values of $g$, even weak NAO events drive significant cooling/warming of the ocean mixed layer. When $g$ is small, there will be little impact of the wind-driven circulation variability on SST, even for strong and persistent phases of the NAO.

\section{c. Experiments with anomalous ocean heat transport}

Three experiments with three different values of $g$ are considered here, together with an experiment with $g=0$, which we will call the "control integration." Particular care must be taken in the choice of values for $g$. By using linear Sverdrup dynamics, Czaja and Marshall (2001) presented a scaling argument that gives a typical change of the intergyre gyre meridional heat transport in the mixed layer of about $0.025 \mathrm{PW}$. This translates into a maximum value of the $\mathbf{Q}$ dipole of around $10 \mathrm{~W}$ $\mathrm{m}^{-2}$. Of the three experiments considered here, one has a lower value than that estimated by Czaja and Marshall (2001), one has a larger value of $g$, and the third has a very much enhanced value. The first column in Table 2 lists the values of $g$ used in the different experiments. We call the first two experiments "weak" and "strong" ocean circulation, and the third "very strong" ocean circulation. In the second column in Table 2, the value of the meridional heat transport at $47^{\circ} \mathrm{N}$ implied by this choice of $g$ is given. This is formally the integral of the dipole in Fig. 3a between latitude $90^{\circ}$ and $47^{\circ} \mathrm{N}$, and for all longitudes, multiplied by $g$.

It is difficult to estimate whether the above values of $g$ and of the associated meridional heat transport change can be considered realistic. One reference is the estimated total annual mean northward ocean heat transport at $47^{\circ} \mathrm{N}$ of about $0.6 \mathrm{PW}$ in the Atlantic (e.g., Ganachaud and Wunsch 2003 or Houghton et al. 1996), a value that could be somewhat higher in winter.

How large is the heat transport anomaly produced in the model with respect to this estimate? Answering this question involves an a posteriori diagnostic of the $Q_{g}^{\prime}$ term in the model integrations, because the $Q$ flux is a result of the full coupled dynamics of the model. These a posteriori estimates are presented in the two last columns of Table 2, where the standard deviation of heat flux at the maximum of the dipole is given, together with the integrated value of meridional transport at $47^{\circ} \mathrm{N}$. Note that the a priori values presented in the second column in Table 2 are considerably higher than actually diagnosed in the model. This is a consequence of the fact that the NAO variance is substantially reduced in the experiments with $g \neq 0$. This power reduction at low frequency is one of the main results of the present paper and will be discussed at length below. In Fig. $3 b$ the latitudinal profile of meridional heat transport variance is given for the weak ocean integration, and in Fig. $3 \mathrm{c}$ a section of the time series $q(t)$, in $\mathrm{W} \mathrm{m}^{-2}$, is shown.

In summary, then, and with the caveat that a substantial part of the observational estimate of 0.6 PW transport may be accomplished by the vertical overturning circulation associated with polar convection, the three experiments have a variability of meridional heat transport that is, respectively, $2 \%, 7 \%$, and $15 \%$ of the total heat carried on average by the ocean at $47^{\circ} \mathrm{N}$.

All experiments comprised two model integrations differing only in their initial conditions. Each integration was run for a spinup period of 3600 days, and then $2 \times 10^{6}$ days were stored. The runs correspond to perpetual winters, but we define $1 \mathrm{yr}$ as a period of 360 days, giving more than $1100 \mathrm{yr}$ of model output per experiment.

\section{Study of interdecadal time scales}

\section{a. Model results}

In this section we analyze the principal modes of variability in each of the four model experiments, on time scales longer than $10 \mathrm{yr}$. The analysis is carried out by performing principal component (PC) analysis on time series of Euro-Atlantic streamfunction fields at the 500$\mathrm{hPa}$ level. The analysis is applied to time series of $25-\mathrm{yr}$ mean maps as well as to series of monthly mean maps. The EOFs of all experiments are practically indistinguishable from one another, both for the monthly mean and for the 25-yr mean case. For example, EOF 1 looks like Fig. 1a for all experiments and for all time averages. This is also true for the other modes of variability (not shown). What changes from one experiment to the 

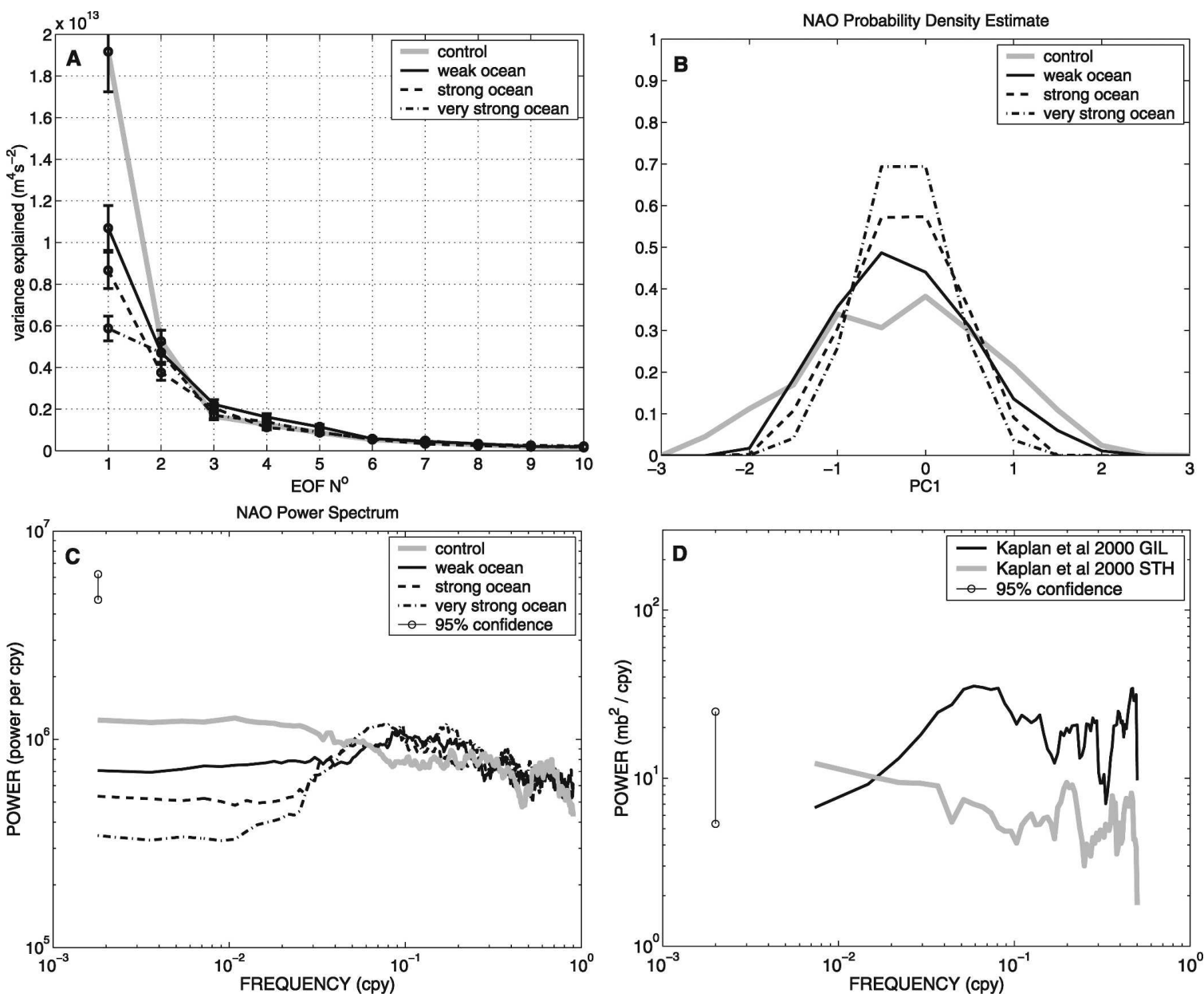

FIG. 4. Illustration of the energy loss of the NAO at low frequencies. (a) First 10 eigenvalues of covariance matrix of 25-yr mean 500-hPa streamfunction. (b) Probability density estimation of PC1 values for 25-yr mean 500-hPa streamfunction. The PCs are divided by the standard deviation of the PC of the control run, and the PDFs are normalized to 1. (c) Multitaper spectrum of monthly mean 500-hPa streamfunction. Each spectrum is the average of two spectra from two parallel integrations. (d) Spectrum of the GIL and of the subtropical high from Kaplan et al. (2000); the $95 \%$ confidence interval is shown.

other is the amount of variance explained by the different modes.

Figure $4 \mathrm{a}$ shows the eigenvalue spectra for the first 10 EOFs computed from 25-yr mean maps for the four experiments. Note that in Fig. 4a, the value of the eigenvalue is plotted and not, as is more common, the percentage of variance explained. To produce this figure, all EOFs were normalized so that the eigenvalues are equal to the variance of each mode, and their sum is the total variance. The statistical uncertainty in the eigenvalues is estimated using the "rule of thumb" of North et al. (1982).

We observe that the first mode of variability - that depicted in Fig. 1a representing the model's NAO-has substantially diminished variance in the $Q_{F}$ integrations with respect to the control. In the weak ocean integration it is reduced by almost half, and in the very strong ocean integration it is reduced by more than two-thirds. The variance explained by the other modes, in contrast, does not vary substantially from one integration to the other. The second, third, and fourth modes exhibit variations within the error bounds, while the higherorder modes have spectra that are virtually indistinguishable from one another. Since the NAO is the principal mode of variability, the total low-frequency variance of the model (the sum of the eigenvalues of Fig. $4 a)$ is also reduced.

The reduction in variability of the NAO at low frequencies can also be seen as a narrowing of the probability density function (PDF) of the first principal component. This is shown in Fig. 4b, where histograms from the PC1 time series are shown. The PCs are computed from monthly mean data and then a low-pass filter of $25 \mathrm{yr}$ is applied. The variances are divided by 
the variance of the control integrations, and the PDFs are normalized to 1 . Note that on increasing $g$, the PDFs become narrower and narrower. An analysis of the third and fourth moments of the distributions (skewness and kurtosis), however, does not show any significant deviation from a normal distribution.

The last panel of Fig. 4 shows that the reduction of variance is found only on time scales longer than decadal. This is clearly demonstrated by the spectrum of the PC1 of monthly mean $500-\mathrm{hPa}$ streamfunction in each of the experiments. Each spectrum in this panel is actually the average of the two spectra from two parallel integrations for each value of the ocean heat transport efficiency. Only frequencies in the range $1 \mathrm{yr}^{-1}$ to around $500 \mathrm{yr}^{-1}$ are shown.

The spectrum of the control integration in which the $Q$ flux is zero (thick gray line) is slightly red and shows no significant peak at any frequency. In the experiments with a $Q$ flux different from zero, however, we find a reduction of power at low frequencies similar to that in Fig. 4a, ranging from a $50 \%$ to a $70 \%$ reduction on passing from weak to very strong ocean heat transport efficiency. The spectra also show a marginally significant increase of power at periodicities of around 10 $\mathrm{yr}$, then decreasing to level out at lower values in the frequency range from $25 \mathrm{yr}^{-1}$ onward. We thus see a spectral "peak" at periodicities of 10-15 yr; this will be further discussed in section 4 .

\section{b. Interpretation}

The reduction of NAO variability seen in Fig. 4 is rather dramatic. Even with the lower value of $g$, which implies rather small anomalous heat fluxes of maximum amplitude of $5 \mathrm{~W} \mathrm{~m}^{-2}$ or so (see section 1c), there is $\sim 50 \%$ reduction in amplitude. The mechanism responsible for this phenomenon can be understood as a delayed negative feedback of ocean circulation on the NAO: the NAO drives the ocean circulation into creating an SST pattern that tends to offset the NAO itself, as described in Marshall et al. (2001a). In this section we explore this mechanism.

To better understand the process, we schematically subdivide it in to three "stages," although this is mainly a conceptual division rather than a temporal one.

1) A period of anomalously positive (negative) phase of the NAO causes, after a delay time $t_{d}$, an anomalously high (low) $Q_{g}^{\prime}$ : that is, an anomalous northward ocean heat transport.

2) The anomalous northward (southward) heat transport creates an SST anomaly dipole in phase with the $Q_{g}^{\prime}$ dipole.
3) The SST anomaly dipole creates an atmospheric response projecting onto a negative (positive) NAO.

Stage 1 follows merely from the definition of $Q_{g}^{\prime}$ in Eqs. (6) and (7). To help understand stages 2 and 3 we will make use of a "prescribed ocean" experiment in which the time series of $Q_{g}^{\prime}$ from the weak ocean integration is prescribed in Eq. (3) and an integration of the coupled model is carried out. This represents the sole feedback of the ocean on the atmosphere, independently of the phase of the NAO.

From this experiment, we computed composites of SST anomaly for periods of strong negative $q(t)$ and subtracted them from composites corresponding to strong positive $q(t)$. The map so obtained, in Fig. 5b, shows the effect of anomalous northward $Q$ flux, illustrating stage 2 above. The SST composites show a dipole with a positive northern lobe of magnitude $0.7 \mathrm{~K}$ and a negative southern lobe of magnitude $0.5 \mathrm{~K}$. The threshold chosen for the composites is one standard deviation of $Q_{g}^{\prime}$, and so the composite SST anomalies can be thought of as created by a total anomalous heat transport of $0.03 \mathrm{PW}$ (cf. Table 2).

Once SST anomalies are created by the $Q$ flux (stage 2), the atmosphere responds to them (stage 3). To demonstrate this phase, it is sufficient to refer back to Fig. 2 in which the response of the atmospheric model to a constant SST anomaly is shown: the response to an SST dipole is an in-phase NAO pattern with a high over warm water and a low over cold water. This is also confirmed by the Z500 composite shown in Fig. 5a from the prescribed ocean experiment. The response to a northward $Q_{g}^{\prime}$ anomaly also has the pattern of a negative NAO. This composite map was obtained for the same periods of strong positive minus strong negative $Q_{g}^{\prime}$ as used to compute Fig. 5b. The amplitude of the responses in Figs. 5 and 2 are compatible: Figure 2, for the constant SST integration, gives $25 \mathrm{~m}$ at $500 \mathrm{hPa}$ for an SST anomaly dipole of amplitude $1.5^{\circ} \mathrm{K}$; Fig. 5, from the prescribed ocean integration, gives $13 \mathrm{~m}$ for $0.5 / 0.7 \mathrm{~K}$.

The atmospheric response to a prescribed mixedlayer heat flux was also analyzed in the Atlantic by Sutton and Mathieu (2002), who forced a coupled GCM with a source of heat resembling the southern lobe of the $Q_{g}^{\prime}$ dipole shown in Fig. 3a. They force with a monopolar $Q$ flux warming of about $40 \mathrm{~W} \mathrm{~m}^{-2}$ in winter but zero in summer, roughly equivalent in magnitude to our strong ocean heat transport experiment. The resulting SST anomaly is found downstream of the maximum prescribed heat flux divergence, which is balanced by a heat flux into the atmosphere. Surface fluxes almost entirely compensate the prescribed heat 

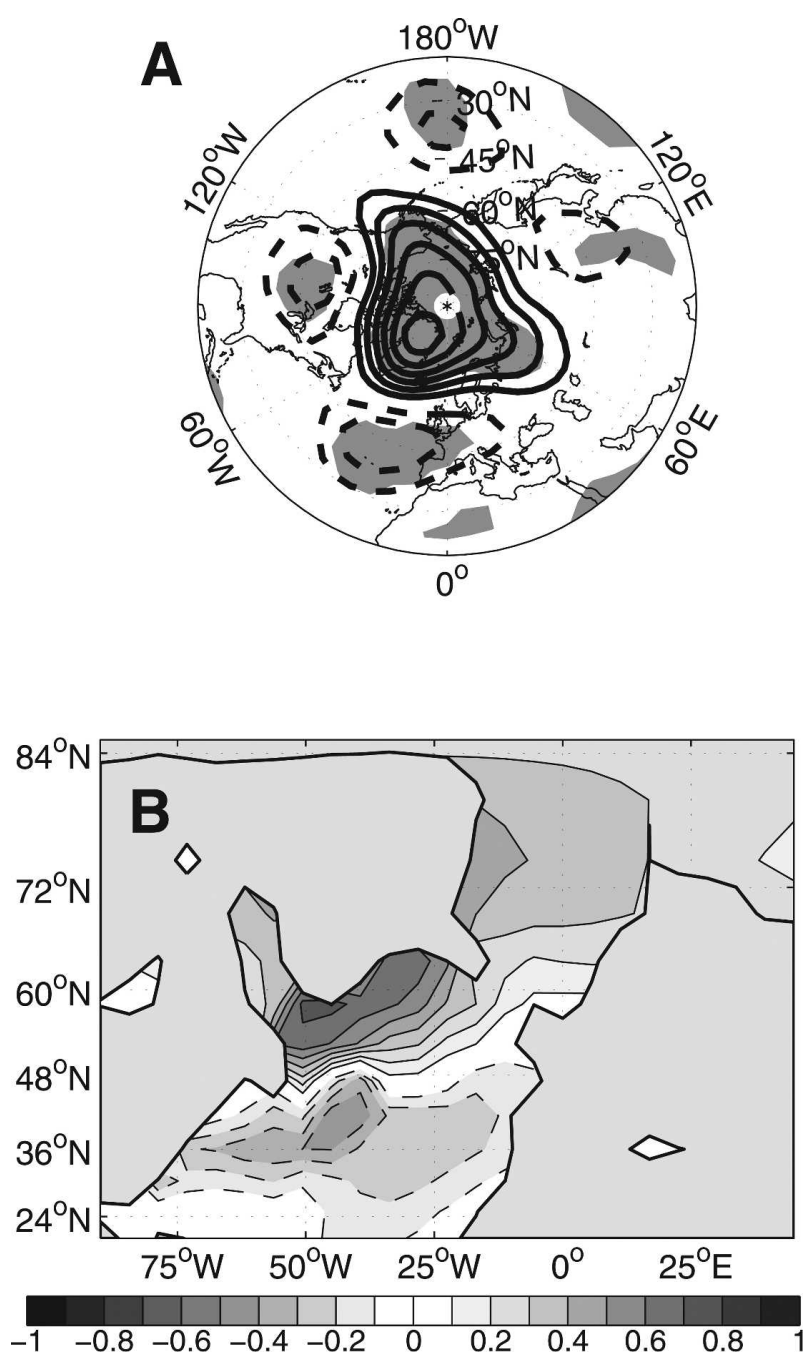

FIG. 5. Composites from the prescribed $Q_{g}^{\prime}$ weak ocean integration, keyed to periods of anomalous northward $Q_{g}^{\prime}$ minus anomalous southward $Q_{g}^{\prime}$. (a) The 500-hPa geopotential height, contoured every $2.5 \mathrm{~m}$; negative contours dashed and zero line omitted. Areas having 99\% confidence according to a Student's $t$ test are shaded gray. (b) SST contoured every $0.1 \mathrm{~K}$; dashed contours negative. Most of the SST composite has $99 \%$ confidence by Student's $t$ test (not shown).

flux convergence, and the atmospheric responsecomprising a low pressure over the heat source and a weak baroclinic vertical structure-creates a downstream SST anomaly. Our scenario is somewhat simpler than that of Sutton and Mathieu (2002), with the SST and heat transport anomaly being in phase.

The prescribed ocean experiment demonstrates only half of the coupled interactions with the NAO; in a fully coupled situation, the SST dipole would be in phase opposition to the NAO pattern. The atmospheric response to the SST dipole, therefore, opposes the NAO. It is not able to offset it entirely, but only weakens it, hence the reduction of power at a frequency lower than $t_{d}$, observed in Fig. 4.

Czaja and Marshall (2001), using the theoretical framework proposed by Marshall et al. (2001b), analyzed the behavior of an idealized model composed of a classical Frankignoul and Hasselmann (1977) stochastic-damped model, complemented by a closure of the form given in Eq. (7) representing the ocean circulation. In their paper, they showed theoretical atmospheric spectra that closely resemble the spectra found here in Fig. 4, including the decrease of power at low frequency, due to a delayed negative feedback.

The somewhat monotonic dependence of the NAO spectral power on the value of $g$ can also be understood in the context of the delayed negative feedback described above. Increasing the efficiency of NAO-induced ocean heat transport efficiency, a larger $Q_{g}^{\prime}$ is produced for the same amplitude of NAO. Hence a larger SST anomaly dipole is produced. Consequently, for a given amplitude of the NAO, the feedback on the atmosphere is larger, resulting in further diminution of the NAO. This can be illustrated by computing a composite atmospheric response figure for a prescribed ocean experiment like that in Fig. 5a, but with larger values of $g$ (not shown). The patterns obtained are the same, but the amplitude of the response increases with $g$.

\section{c. Comparison with observations}

Several estimates of NAO power spectrum have been proposed in the literature. Although determining spectral power at decennial time scales is very difficult due to lack of data, the consensus is that the NAO, at time scales longer than a year, has a spectral power that seems to slightly exceed that expected from a purely stochastic red noise process (see the recent reviews by Hurrel et al. 2003 and Czaja et al. 2003).

The model NAO for the control experiment $\left(Q_{g}^{\prime}=0\right.$; Fig. $4 c$ gray curve) also shows a red spectrum. However, as we increase the role of ocean dynamics in our coupled model, we find that the NAO spectrum becomes "bluer," with less energy at longer time scales (Fig. 4c black curves). The effect of ocean circulation in this model is meant to represent the effect of winddriven circulation. As emphasized in the conclusions below, one might expect other processes (e.g., thermohaline circulation) to introduce variability on time scales longer than that of ocean gyres, thereby perhaps masking their blue spectrum signature. However, Czaja and Marshall (2001), based on sea level pressure data from Kaplan et al. (2000), noted that when the northern [Greenland-Iceland low (GIL) region] and southern [subtropical high (STH)] centers of action of the NAO are studied separately, the two regions exhibit different 
low-frequency behavior. The spectrum of GIL and STH are shown in Fig. 4d; a red spectrum is found in the region of the subtropical high (gray line in Fig. 4d), whereas GIL (black line) has a blue spectrum, similar to the one obtained in the weak ocean experiment (Fig. $4 \mathrm{c}$, continuous black) presented here. The statistical significance of the spectra of Czaja and Marshall (2001) is only marginal, but their results tentatively suggest that the NAO index, being traditionally taken as a normalized pressure difference between these two regions, is dominated by the subtropical high, its more energetic component at long time scales. Such a hypothesis is difficult to test convincingly with short and noisy observational records, which have error bar comparable to those in Fig. 4d. It could nevertheless be investigated further in more realistic coupled model simulations.

\section{Decadal time scales: An oscillation}

The existence of a negative delayed feedback of the ocean mixed layer on the NAO leads to a coupled oscillation in our simulations, on time scales close to $t_{d}(10$ $y r)$. This is illustrated here for the strong ocean experiment $(g=24)$. Weaker values of the control parameter $g$, that is, less efficient wind-driven response to NAO forcing, led to an identifiable oscillatory signal in SST but not in atmospheric fields. This reflects the strong background of intrinsic variability in the NAO, which limits our ability to detect such oscillatory signals unless they become sufficiently strong.

Figure 6 is a (lagged) composite map of SST (shading) and 500-mb geopotential height (Z500, contours) annual anomaly based on the time series of the model SST-EOF 1 (i.e., the first principal component SSTPC1). When SST and Z500 anomalies are averaged at times when the SST-PC1 is strong (zero lag), the expected relationship between a negative NAO phase and a warmer subpolar gyre and a colder subtropical gyre is found. This anomalous SST pattern simply reflects the structure of the SST-EOF1 (Fig. 1) and is consistent with the ocean's response to atmospheric forcing.

When SST and Z500 anomalies are averaged $3 \mathrm{yr}$ after strong SST-PC1 events (lag +3), there is little signal in either the atmosphere or the ocean. On the other hand, at a lag of +6 and +9 yr, one again observes the NAO/SST dipole relationship but with reversed signs, that is, a positive NAO phase associated with a colder subtropical gyre and a warmer subtropical gyre. Another sign reversal can be seen at a lag of $15 \mathrm{yr}$, yielding a relationship similar (but weaker-note the change of scale) to that seen at zero lag. At longer lags, the composites become noisy and are not shown. Overall, Fig. 6 suggests a damped oscillation in the ocean and the atmosphere with a period of about $15 \mathrm{yr}$. Typical amplitudes of Z500 and SST anomalies are small, of order of 5-10 m and $0.2-0.3 \mathrm{~K}$, respectively. This composite analysis is consistent with a spectral peak at periods of 10-15 yr found in Fig. 4c above.

Several mechanisms can be invoked to explain this oscillation. In the previous section we have argued that on time scales that are long compared to the delay $t_{d}$ (interdecadal time scales), a destructive interference between the atmospheric response to SST and the NAO is responsible for reduced energy levels in the ocean and the atmosphere. This suggests that at some shorter time scale, there might be a constructive interference between them, yielding a preferred time scale of variability. Since the oscillation is seen both in the ocean and the atmosphere, it is likely to be of coupled origin. Indeed, our model was designed to mimic the simpler analytical coupled model of Marshall et al. (2001b), which, for sufficiently efficient ocean heat transport and moderate air-sea feedback, predicts a coupled decadal oscillation just like that studied here. In Marshall et al. (2001b), the time scale of the oscillation was primarily controlled by the delay time $t_{d}$, and the mechanism of the oscillation was akin to that of the delayed oscillator models introduced for ENSO studies.

To prove that coupling is indeed crucial for the oscillation, we conducted a "passive ocean" experiment, forcing the SST Eq. (3) offline with the atmospheric fields extracted form the control integration. For this experiment $g$ was set at the same value of $24 \mathrm{~W} \mathrm{~m}^{-2}$ as in the strong ocean integration. In this case (not shown) the oscillation disappeared.

Owing to the paucity of in situ observations over the oceans and the limited length of the available time series, a direct comparison with observed data is difficult. We note, however, that the existence of a decadal timescale oscillation over the North Atlantic sector has been suggested in several observational studies. Deser and Blackmon (1993) showed indication of a weak spectral peak at a time scale of $\sim 12 \mathrm{yr}$ in in situ observations of surface wind, sea level pressure, surface air temperature, and SST over the period 1900-89. Czaja and Marshall (2001), using a longer observational record (18601998), also found evidence of a damped decadal oscillation in SST (but not in sea level pressure). Their composite map of SST (Czaja and Marshall 2001, their Fig. 3) is very similar to Fig. 6, except for a slightly longer time scale.

In our simulations, it was only for sufficiently strong values of the control parameter $g$ that we were able to clearly isolate the oscillation in atmospheric fields. The fact that in observational studies enhanced decadal variability is more robustly detected in SST than in at- 

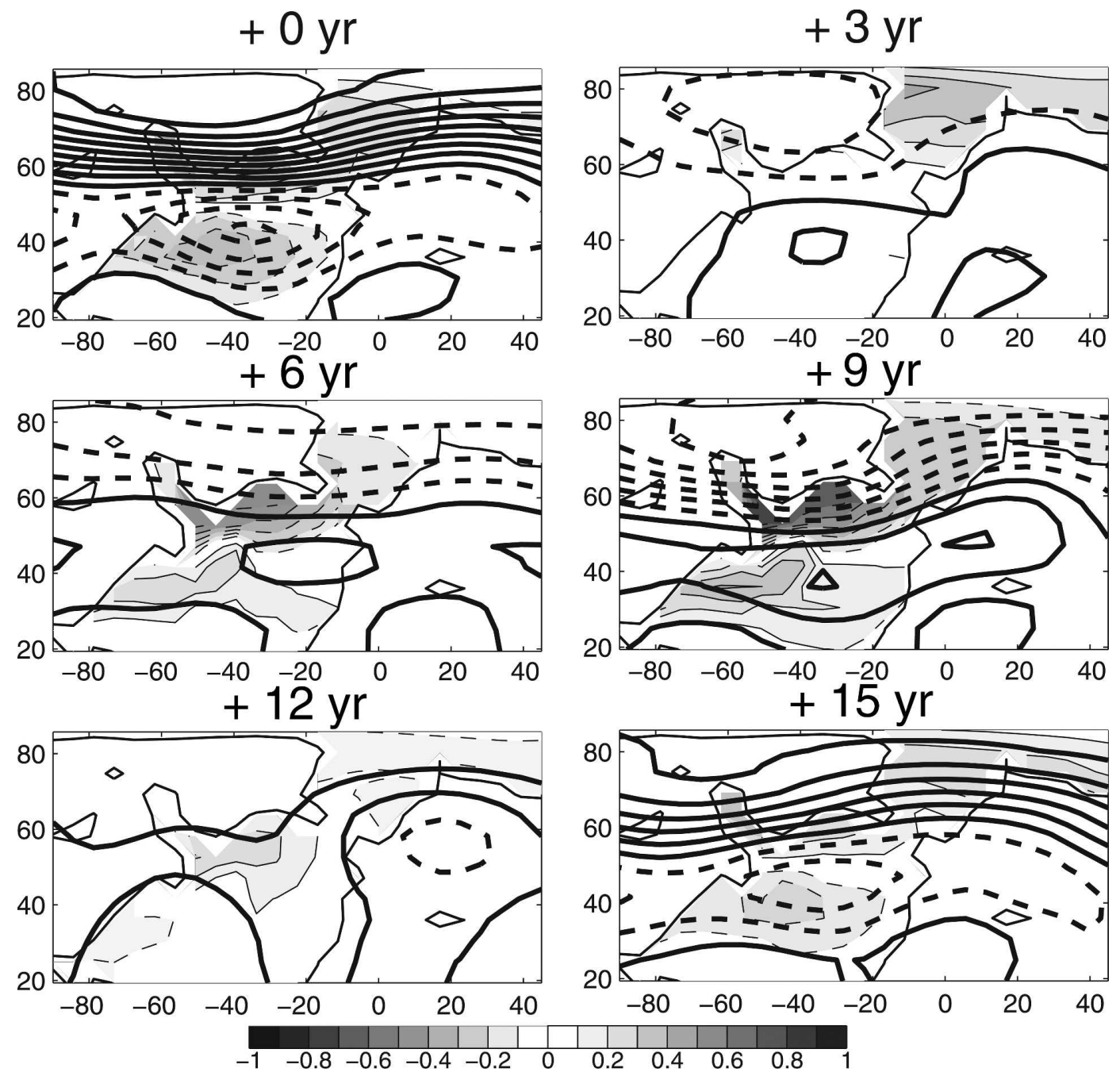

FIG. 6. Composites of annual mean SST (gray shading) and 500-hPa GPH (black lines), keyed to the first PC of SST with a threshold of one standard deviation. For 500-hPa GPH, contours are every $2.5 \mathrm{~m}$. Both variables are divided by a factor of 5 at 0 -yr lag. Negative contours are dashed. The main features of both SST and GPH satisfy a Student's $t$ test at $99 \%$ confidence (not shown).

mospheric variables suggests that the North Atlantic wind-driven circulation only interacts weakly with the NAO. In other words, our experiment labeled weak ocean is probably more relevant to the observed climate.

\section{Discussion and conclusions}

In this paper, a simplified yet realistic coupled model is used to study the effect of North Atlantic Ocean circulation on the atmospheric variability at decennial to longer time scales. Changes in ocean circulation are represented in the model by anomalous meridional heat transport due to the changes in the wind-driven gyre system. The NAO drives an anomalous heat trans- port across the gyres separator, in what was called intergyre-gyre by Marshall et al. (2001b). High positive (negative) NAO causes an anomalous northward transport that warms (cools) the subpolar gyre and cools (warms) the subtropical one. In the model, this phenomenon is represented by an anomalous surface heat flux $Q_{g}^{\prime}$, parameterized as a delayed modulation of a prescribed pattern. The pattern is a dipole having zero line in phase with the zero line of the NAO pattern. The delayed modulation is introduced to account for the response time $t_{d}$ of the ocean to changes in winds, and it is chosen to be equal to $10 \mathrm{yr}$.

The relevance of our study to climate variability depends on the ability of our model to capture observed patterns of variability and their response to SST 

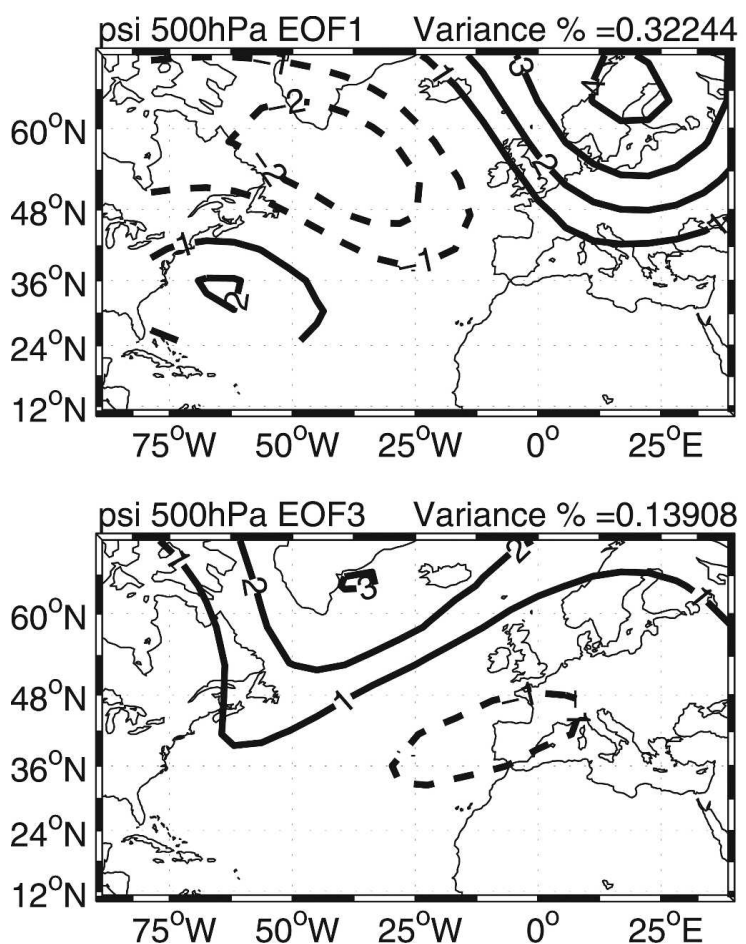
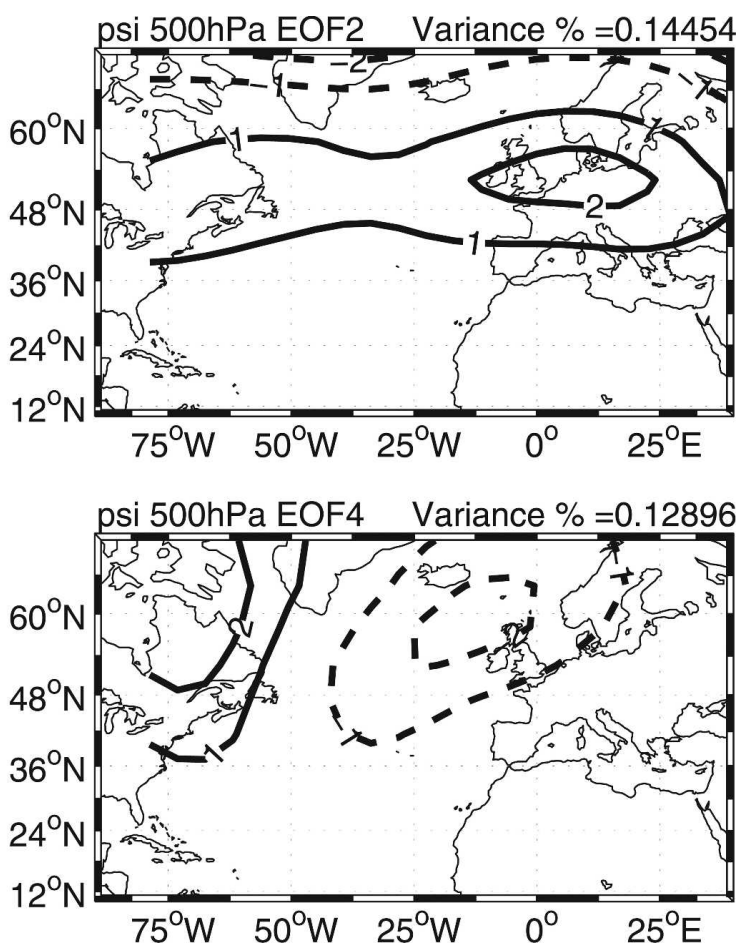

FIG. 7. Vanishing of the NAO: EOFs of 500-hPa streamfunction of the integration with $g=240$. Same as Fig. 1 except contour interval of $1 \mathrm{~m}$.

anomalies. Patterns of variability were diagnosed and favorably compared to observations. Atmospheric mean response was also diagnosed and found to be consistent with the results of a majority of full-fledged GCMs, as reported by Kushnir et al. (2002).

Depending on the time scale relative to $t_{d}$, two types of response were found on the variability of the atmosphere to the anomalous heat flux $Q_{g}^{\prime}$. At a time scale longer than $t_{d}$, the $Q_{g}^{\prime}$ parameterization produces a negative feedback: the SST pattern generated by the NAO through the $Q_{g}^{\prime}$ creates an atmospheric response that tends to offset the NAO itself. This mechanism becomes stronger and stronger, increasing the parameter $g$ that determines the amplitude of the $Q_{g}^{\prime}$ for a given NAO amplitude.

This effect can be taken to the extreme by greatly increasing the value of $g$ so as to give a very strong negative feedback. To illustrate this, we performed an integration setting $g=240 \mathrm{~W} \mathrm{~m}^{-2}$. While this high efficiency of heat transport by the NAO is obviously not realistic, it has the interesting effect of completely shutting off the NAO itself at low frequencies. In Fig. 7 the first four Euro-Atlantic 500-hPa streamfunction EOFs of this integration are shown: it is clear that the NAO (cf. with Fig. 1a) is no longer one of the principal modes of variability. The variance explained by the NAO for this new integration becomes so small as to be relegated to the lower part of the eigenvalue spectrum.

At time scales of around $t_{d}$, the $Q_{g}^{\prime}$ parameterization produces the dynamics of a delayed oscillator, and a damped coupled oscillation is found in the SST and geopotential height. An alternative explanation for the increase of power in the 10-15-yr band in the SST field was given by Saravanan and McWilliams (1998) in terms of "advective resonance," that is, a passive response of the ocean to stochastic atmospheric forcing in which a time scale is picked out that is that of mean geostrophic advection over the spatial scale imposed by the atmospheric forcing. A different, coupled mechanism is at play in our model because there is no mean flow advection, and hence advective resonance is absent by construction.

Our results suggest that at very long time scales, the wind-driven circulation can only have a damping effect on the NAO spectrum. Since there is only a small hint of blueness in the observed NAO spectrum (with the possible exception of the GIL spectrum in Czaja and Marshall 2001; see discussion above), other mechanisms must therefore be responsible for its sustained energy at low frequencies. It has been suggested that at low frequencies coupled variability is mainly linked to the thermohaline circulation (THC). Different processes are responsible for THC variability, which may not be controlled by the NAO, but that could create an 
SST pattern able to enhance its variability. Nevertheless, although there is modeling evidence of the impact of the NAO on the THC, the patterns of SST on which this coupling would project remains unclear. Delworth and Mann (2000) found a coupled mode of variability in a long GCM integration, characterized by a time scale of variability of around $60 \mathrm{yr}$. This mode compares well with that found by Kushnir et al. (1997) in observations, which in the northern Atlantic region is characterized by a monopolar pattern of SST and sea level pressure covering the whole basin.

The structure of the anomalous SST pattern associated with the THC variability is fundamental. If, as suggested in Marshall et al. (2001b), it had the shape of a dipole concentrated in the northern part of the basin, the same mechanism invoked here for the wind-driven circulation could also be applied to the THC, leading to a further damping of the NAO on long time scales. In that case, other mechanisms should be investigated for explaining the NAO spectral power at low frequency.

A parameterization of THC similar to the one used here for wind-driven circulation, using different spatial patterns and time dependence, can be devised and will be the object of future work. Furthermore, other directions of investigation are suggested by the use of this model. For example the effect of the presence of the decadal oscillation on seasonal and longer predictability can be investigated. Moreover, air-sea coupling can be applied to other regions of the world, such as the North Pacific or the Antarctic Ocean.

Acknowledgments. The authors wish to thank Franco Molteni and David Ferreira for interesting discussions. The work was partially supported by NOAA's Office of Global Programs.

\section{APPENDIX A}

\section{Full Atmospheric Equations}

The full equations of the atmospheric model discretized on three levels (1,2, and 3 from top to bottom) are

$$
\begin{aligned}
\frac{\partial}{\partial t} q_{1}= & -J\left(\psi_{1}, q_{1}\right)-D_{1}(\psi)+S_{1}, \\
\frac{d}{d t} q_{2}= & -J\left(\psi_{2}, q_{2}\right)-D_{2}(\psi)+\frac{f_{0}}{\Delta p \sigma_{2}} \frac{R}{p} \chi_{\text {atl }} \frac{Q_{s}}{\rho_{a} c_{p a} h_{a}} \\
& +S_{2} \text { and } \\
\frac{d}{d t} q_{3}= & -J\left(\psi_{3}, q_{3}\right)-D_{3}(\psi)-\frac{f_{0}}{\Delta p \sigma_{2}} \frac{R}{p} \chi_{\text {atl }} \frac{Q_{s}}{\rho_{a} c_{p a} h_{a}}+S_{3},
\end{aligned}
$$

where $J(\cdot, \cdot)$ is the Jacobian operator and $\psi$ is the streamfunction. The QG PV is $q$, including the effect of orography on the lower layer. It is related to the streamfunction by a linear operator whose discretized definition can be found on MM93. The PV and streamfunction are computed at the three dynamical levels; temperature is diagnosed at the intermediate layers 500-800 and 200-500. Linear dissipation terms are represented by $D_{1}, D_{2}$, and $D_{3}$.

The third term on the rhs. of Eqs. (A2) and (A3) represents the PV forcing associated with the surface heat flux. All the heat is deposited between the two lower levels of the model and is scaled by the average thickness of the 500-800-layer $h_{a}$. It has the effect of changing the thickness of the layer; a negative flux $Q_{s}$ (which by convention corresponds here to heating) induces an increase in thickness. It can be seen that if $Q_{s}$ is negative, there is a negative PV forcing at level 2, that is, a positive streamfunction tendency; at level 3 the forcing is equal and opposite in sign, hence creating a negative streamfunction tendency. The model is coupled to the SST equation over the North Atlantic basin. This is expressed in Eqs. (A2) and (A3) by the function $\chi_{\text {att }}$, that is set equal to one over the North Atlantic basin and zero elsewhere.

The meaning of all the other parameters and variables in Eqs. (A1)-(A3) are listed in Table 1.

\section{APPENDIX B}

\section{Average Source Terms}

In the atmospheric model, Eqs. (A1)-(A3), the timeindependent forcings $S_{1}, S_{2}$, and $S_{3}$ include sources of potential vorticity that result from processes not explicitly included in the equations: radiative forcing, other diabatic heat fluxes (linked, e.g., to precipitation), and the effect of divergent flow. In addition the forcing implicitly contains the effects of subgrid-scale processes. The forcing term has been estimated empirically following MM93 as follows.

From a long series of wintertime analyzed states, one can substitute $\hat{q}$ and $\hat{\psi}, \hat{u}_{s}, \hat{T}_{a}$, and $\widehat{\text { SST }}$ into Eqs. (A1)(A3), where the hat indicates observed field unless specified, and then take the time average (represented by the overbar). This gives an equation for $S_{i}$. For example, for level 2,

$$
\begin{aligned}
S_{2}= & \overline{J\left(\hat{\psi}_{2}, \hat{q}_{2}\right)}+D_{2}(\overline{\hat{\psi}}) \\
& -\frac{f_{0}}{\Delta p \sigma_{2}} \frac{R}{p} \frac{C_{D}}{h_{a}}\left(1+B^{-1}\right) \overline{\left|\hat{u}_{s}\right|\left(\hat{T}_{a}-\overline{\overline{\mathrm{SST}}}\right)}
\end{aligned}
$$


Here the term $\overline{\overline{\mathrm{SST}}}$ appearing in the third term on the rhs is the observed mean December-January-February (DJF) SST.

Daily streamfunction fields were used from the European Centre for Medium-Range Weather Forecasts (ECMWF) operational analysis for DJF 1979-89. From these, the corresponding values of $q, u_{s}$, and $T_{a}$ were computed.

The source term in the SST equation $S_{c}$-see Eq. (3) - acts as a flux correction term. It is computed in a similar way to the atmospheric forcing terms $S_{1}, S_{2}$, and $S_{3}$, by substituting in to Eq. (3) a large dataset of atmospheric fields, keeping a constant DJF SST, and taking the time average. Since $Q_{g}^{\prime}$ has zero time mean by definition, we obtain the following equation for $S_{c}$ :

$$
\begin{aligned}
S_{c}= & -\rho_{a} c_{p a}\left(1+\frac{1}{B}\right) C_{D} \overline{\left|\hat{u}_{s}\right|\left(\hat{T}_{a}-\overline{\overline{\mathrm{SST}}}\right)} \\
& -\rho_{o} c_{p o} h_{m} \hat{\mathbf{V}}_{\mathrm{ek}} \cdot \nabla \overline{\overline{\mathrm{SST}}} .
\end{aligned}
$$

Here $\hat{\mathbf{V}}_{\mathrm{ek}}$ is computed according to the bulk definition Eq. (5):

$$
\mathbf{V}_{\mathrm{ek}}=\left(-\frac{\overline{\hat{\tau}_{y}}}{\rho_{o} f_{0} h_{m}}, \frac{\overline{\hat{\tau}_{x}}}{\rho_{o} f_{0} h_{m}}\right) \text { and } \overline{\hat{\tau}}=\rho_{a} C_{D} \overline{\left|\hat{u}_{s}\right| \hat{\mathbf{u}}_{s}} .
$$

In this case, however, the atmospheric fields $\hat{u}$ and $\hat{T}_{a}$ are obtained from a long integration of the atmospheric model, forced by $S_{1}, S_{2}$, and $S_{3}$ computed as above and using a constant observed sea surface temperature field $\overline{\mathrm{SST}}$. In this way, the SST equation is equilibrated to the actual climate of the atmospheric model.

Note that $S_{c}$ can be interpreted as the sum of an estimate of the model's climatological surface and Ekman fluxes (with reversed sign): $S_{c}=-\bar{Q}_{s}-\bar{Q}_{\mathrm{ek}}$, where $\bar{Q}_{s}$ and $\bar{Q}_{\text {ek }}$ are the first and second term on the rhs of Eq. (B2). In this sense, the slab mixed layer Eq. (3) can also be seen as, and it is actually formally equal to, an equation for SST anomalies forced by anomalous heat fluxes.

\section{REFERENCES}

Barsugli, J. J., and D. S. Battisti, 1998: The basic effects of atmosphere-ocean thermal coupling on midlatitude variability. $J$. Atmos. Sci., 55, 477-493.

Battisti, D. S., U. S. Bhatt, and M. A. Alexander, 1995: A modeling study of the interannual variability of the North Atlantic Ocean. J. Climate, 8, 3067-3083.

Cayan, D. R., 1992: Latent and sensible heat flux anomalies over the northern oceans: Driving the sea surface temperature. $J$. Phys. Oceanogr., 22, 859-881.

Czaja, A., and J. Marshall, 2001: Observations of atmosphere- ocean coupling in the North Atlantic. Quart. J. Roy. Meteor. Soc., 127, 1893-1916.

_ , and C. Frankignoul, 2002: Observed impact of North Atlantic SST anomalies on the North Atlantic Oscillation. $J$. Climate, 15, 606-623.

— A. Robertson, and T. Huck, 2003: The role of coupled processes in producing NAO variability. North Atlantic Oscillation: Climatic Significance and Environmental Impact, Geophys. Monogr., No. 134, Amer. Geophys. Union, 147-172.

D'Andrea, F., and R. Vautard, 2000: Reducing systematic errors by empirically correcting model errors. Tellus, $\mathbf{5 2 A}, 21-41$.

Delworth, T. L., and R. J. Greatbatch, 2000: Multidecadal thermohaline circulation variability driven by atmospheric surface flux forcing. J. Climate, 13, 1481-1495.

— , and M. E. Mann, 2000: Observed and simulated multidecadal variability in the North Atlantic. Climate Dyn., 16, 661676.

Deser, C., and M. L. Blackmon, 1993: Surface climate variations over the North Atlantic during winter: 1900-1989. J. Climate, 10, 393-408.

Feldstein, S. B., 2000: The timescale, power spectra, and climate noise properties of teleconnection patterns. J. Climate, 13, 4430-4440.

Ferreira, D., and C. Frankignoul, 2005: The transient atmospheric response to midlatitude SST anomalies. J. Climate, 18, 10491067.

Frankignoul, C., and K. Hasselmann, 1977: Stochastic climate models. Part II: Application to sea-surface temperature variability and thermocline variability. Tellus, 29, 289-305.

— , P. Muller, and E. Zorita, 1997: A simple model of the decadal response of the ocean to stochastic wind forcing. J. Phys. Oceanogr., 27, 1533-1546.

Ganachaud, A., and C. Wunsch, 2003: Large-scale ocean heat and freshwater transports during the World Ocean Circulation Experiment. J. Climate, 16, 696-705.

Houghton, J. T., L. G. Meira Filho, B. A. Callander, N. Harris, A. Kattenberg, and K. Maskell, Eds., 1996. Climate Change 1995: The Science of Climate Change. Cambridge University Press, 572 pp.

Hurrel, J. W., Y. Kushnir, G. Ottersen, and M. Visbek, 2003: An overview of the North Atlantic Oscillation. North Atlantic Oscillation: Climatic Significance and Environmental Impact, Geophys. Monogr., No. 134, Amer. Geophys. Union, 147172.

Kaplan, A., Y. Kushnir, and M. Cane, 2000: Reduced space optimal interpolation of historical marine sea level pressure: 1854-1992. J. Climate, 13, 2987-3002.

Kushnir, Y., Y. Tourre, and B. Rajagopalan, 1997: Decadal and multidecadal variability in Atlantic SST and sea level pressure. Proc. Atlantic Climate Variability Meeting, Lamont, NJ, Lamont Doherty Earth Observatory, Columbia University. [Available online at http://www.aoml.noaa.gov/phod/acvp/ cover.htm.]

_, W. A. Robinson, I. Bladé, N. M. J. Hall, S. Peng, and R. Sutton, 2002: Atmospheric GCM response to extratropical SST anomalies: Synthesis and evaluation. J. Climate, 15, 2233-2256.

Marshall, J., and F. Molteni, 1993: Toward a dynamical understanding of planetary-scale flow regimes. J. Atmos. Sci., 50, 1792-1818.

_- and Coauthors, 2001a: North Atlantic Climate Variability: Phenomena, impacts and mechanisms. Int. J. Climatol., 21, 1863-1898. 
— action of the North Atlantic Oscillation with the ocean circulation. J. Climate, 14, 1399-1421.

North, G. R., T. L. Bell, R. F. Cahalan, and F. J. Moeng, 1982: Sampling errors in the estimation of empirical orthogonal functions. Mon. Wea. Rev., 110, 699-706.

Rodwell, M. J., and C. K. Folland, 2002: Atlantic air-sea interaction and seasonal predictability. Quart. J. Roy. Meteor. Soc., 128, 1413-1443.

— D. P. Rowell, and C. K. Folland, 1999: Oceanic forcing of the wintertime North Atlantic Oscillation and European climate. Nature, 398, 320-323.

Saravanan, R., and J. C. McWilliams, 1998: Advective oceanatmosphere interaction: An analytical stochastic model with implications for decadal variability. J. Climate, 11, 165-188.

Stephenson, N. C., V. Pavan, and R. Bojariu, 2000: Is the North Atlantic Oscillation a random walk? Int. J. Climatol., 20, $1-18$.
Sutton, R. T., and P-P. Mathieu, 2002: Response of the atmosphere-ocean mixed layer system to anomalous ocean heat flux convergence. Quart. J. Roy. Meteor. Soc., 128, 1259 1275 .

- and D. L. R. Hodson, 2003: Influence of the ocean on North Atlantic climate variability 1871-1999. J. Climate, 16, 32963313.

Thompson, D., S. Lee, and M. P. Baldwin, 2003: Atmospheric processes governing the North Atlantic Oscillation/Northern Hemisphere annular mode. North Atlantic Oscillation: Climatic Significance and Environmental Impact, Geophys. Monogr., No. 134, Amer. Geophys. Union, 81-112.

Visbeck, M., R. Curry, B. Dickson, E. Chassignet, T. Delworth, and G. Krahman, 2003: The ocean's response to North Atlantic Oscillation variability. North Atlantic Oscillation: Climatic Significance and Environmental Impact, Geophys. Monogr., No. 134, Amer. Geophys. Union, 113-145. 